\title{
Fucoxanthin improves functional recovery of orbitopathy in Graves' disease by downregulating IL-17 mRNA expression in a mouse model
}

\author{
Lichao Chai ${ }^{1}$, Jing Wang ${ }^{2 *}$, Yan Wei ${ }^{1}$ \\ ${ }^{1}$ Department of Nuclear Medicine, ${ }^{2}$ Department of Nephrology, Xingtai People's Hospital, Xigtai 054031, China \\ *For correspondence: Email: jacksonhardingzoy@yahoo.com; Tel: 0086-0319-3286014 \\ Sent for review: 11 December 2019 \\ Revised accepted: 22 April 2020
}

\begin{abstract}
Purpose: To explore the efficacy of fucoxanthin (FX), a carotenoid, against inflammation via inhibition of IL-17 mRNA expression, and its anti-oxidant activity in Graves' orbitopathy (GO)-induced mice model. Methods: The effects of FX on IL-6, IL-8, IL-17, MCP-1, and TNF- $\alpha$, in orbital fibroblast tissues extracted from GO-induced BALB/c mice was investigated. Anti-oxidative stress markers, 8-hydroxy-2'deoxyguanosine (8-OHdG) and malondialdehyde (MDA) levels were quantified in tear samples collected from GO-induced FX treated mice.

Results: FX administration in cultured human orbital fibroblast cells revealed almost complete cell viability and no cell apoptosis. FX resulted in IL-1 $\beta$ induced Beclin-1 and Atg-5 silencing, in cultured human orbital fibroblasts. BALB/c mice immunized with Ad-TSHR289 indicated elevated levels of thyroid peroxidase and thyroglobulin antibodies in the serum sample. FX predominantly downregulated the mRNA expression of IL-17, and also reduced increased 8-OHdG and MDA in the tear secretion of GO-induced mice.

Conclusion: FX may be an effective and useful molecule for the treatment of GO, through its antiinflammatory and anti-oxidative potential, but it requires further investigation to ascertain its therapeutic effectiveness.
\end{abstract}

Keywords: Anti-inflammatory, Anti-oxidant, Fucoxanthin, Graves' disease, Graves' orbitopathy, IL-17

This is an Open Access article that uses a fund-ing model which does not charge readers or their institutions for access and distributed under the terms of the Creative Commons Attribution License (http://creativecommons.org/licenses/by/4.0) and the Budapest Open Access Initiative (http://www.budapestopenaccessinitiative.org/read), which permit unrestricted use, distribution, and reproduction in any medium, provided the original work is properly credited.

Tropical Journal of Pharmaceutical Research is indexed by Science Citation Index (SciSearch), Scopus, International Pharmaceutical Abstract, Chemical Abstracts, Embase, Index Copernicus, EBSCO, African Index Medicus, JournalSeek, Journal Citation Reports/Science Edition, Directory of Open Access Journals (DOAJ), African Journal Online, Bioline International, Open-J-Gate and Pharmacy Abstracts

\section{INTRODUCTION}

Graves' disease (GD) and Hashimoto's thyroiditis $(\mathrm{HT})$ are the two most predominant organspecific autoimmune thyroid disorder (AITD). Upregulation of thyrotropin receptor specific stimulatory autoantibodies induce increased thyroid hormone production, leading to hyperthyroidism, and condition termed as
Graves' disease [1]. Hyperthyroidism resulted due to thyroid breakdown triggered by thyroid specific T-cell mediated immune response leading to HT [2]. The global incidence of GD is increasing progressively and the prevalence of GO is indicated in half of the individuals suffering from GD [3,4]. Patients with GO experience severe and sharp pain due to inflammation, diplopia and optic neuropathy and may cause 
irreversible vision loss [5]. This cellular infiltration of mast cells coupled with cytokine production and its effect on fibroblasts in the orbit initiates remodeling in orbital tissues. Increased cytokine levels trigger the orbital fibroblast proliferation, adipose tissue enlargement and increased glycosaminoglycan secretion from fibroblasts [6]. Thyrocytes and orbital fibroblasts are known to synthesize interleukin (IL)-1, IL-6, IL-16, RANTES, and CXCL-10. RANTES and IL-16 have been identified as critical T-lymphocytes chemoattractant moieties [7].

Inflammatory and autoimmune diseases have been known to be caused by the involvement of CD4+ T-helper lymphocytes. Series of CD4+Tcells, identified as $\mathrm{TH} 17$ cells are attributed to the production of IL-17 [8]. Critical immune responses by Th17 cells have been identified in autoimmune diseases namely, rheumatoid arthritis, systemic lupus erythematosus, and psoriasis [9]. Cytokines with proinflammatory functionality, secreted by Th17 cells include IL17, IL-21, and IL-22. Thus, Th17 cells and IL-17 critically contribute to various autoimmune diseases such as AIRD and GD [10,11].

IL-17 promotes the migration of leucocytes and intensifies the expression of IL-1, IL-6, and TNF$\alpha$ [12]. Recent investigations provide evidence that Th17 lymphocyte level increases in patients with Graves' disease [13]. Overexpression of IL17 in pathophysiological events involves recruitment of effector leukocytes and inflammation at the site of GO.

Fucoxanthin (FX), a non-provitamin-A marine carotenoid, is known to possess activities against inflammation, oxidative stress, cancer, diabetes, and obesity. Anti-inflammatory effect of FX has been proved against lipopolysaccharide-induced inflammation in murine RAW 264.7 culture system [14]. Neuroinflammation, induced by amyloid- $\beta 42$ and lipopolysaccharide in BV2 microglia cells can be regulated through negative feedback by FX [15]. A dose-dependent lowering of COX-2 and iNOS have been documented with FX administration [16]. Literature reveals that on oral administration, FX inhibits Th17 cell differentiation, and induces the development of Treg cells. [17]. This explains the antiinflammatory effect of FX by inhibition of IL-17.

Critical involvement of IL-17 producing Th17 cells in GO and their active participation in the pathogenesis of such devastating autoimmune diseases had propelled the investigation to find novel and safe therapeutics. Hence, the work was carried out to explore the possible effect and mechanism of $\mathrm{FX}$ in attenuation of inflammation caused during $\mathrm{GO}$.

\section{EXPERIMENTAL}

\section{Animals}

Procurement of female BALB/c mice (9 - 10 weeks old) was done from Vital River Laboratory Animal Technology Co. Ltd (Beijing, China). All the procedures conducted on animals were approved by Guidelines for Animal Experiments of Xingtai People's Hospital, Xingtai, China (Approval No. XPHIEC/2018/42), in line with international guidelines for animal studies (18). The animals were housed in a clean and hygienic environment, and the experiments were performed in pathogen-free facility, with $50-60$ $\%$ humidity and $21-25^{\circ} \mathrm{C}$ temperature.

\section{Cell viability assay}

Cells from human orbital fibroblasts $\left(1 \times 10^{4}\right.$ cells $/ \mathrm{mL}$ ) (Procell Life Sciences Co. Ltd., China) were placed in 96-well plates and were incubated for one day. The plates were treated with increasing concentration of $\mathrm{FX}(0,1.0,2.5,5.0$ and $10 \mu \mathrm{M}$ ) and incubated at $37^{\circ} \mathrm{C}$ for $24 \mathrm{~h}$. Cell Counting Kit-8 (CCK-8) assay kit solution was then added to the plates and after incubating at $37{ }^{\circ} \mathrm{C}$ for $1 \mathrm{~h}$, the optical density was recorded using a Multiskan microplate reader at $450 \mathrm{~nm}$ (Thermo Fisher Scientific, Germany). Results indicating cell viability were recorded considering experimental, blank and control results.

\section{Apoptosis assay}

The cultured human orbital fibroblast cells were collected and rinsed with PBS solution, and $1 \times$ $10^{6}$ cells were seeded in cell culture plates with 6 wells. After 24-hour incubation, the cell cultures were transferred and incubated for further $24 \mathrm{~h}$ at $37^{\circ} \mathrm{C}$ in serum-free DMEM with and without $1 \mu \mathrm{M}$ FX. The cells were removed and digested with trypsin and subjected to $300 \mathrm{xg}$ centrifugation for $12 \mathrm{~min}$ at $4^{\circ} \mathrm{C}$. The cells were washed with cold physiological buffer saline solution and dispersed in a mixture of annexin V-FITC binding buffer $(195 \mathrm{~mL})$ and annexin V-FITC (5 mL), and to this $10 \mathrm{~mL}$, propidium iodide solution was added. The mixture was allowed to rest at room temperature in the dark. Finally, FACS Calibur flow cytometer was used to quantify cytometry (BD Biosciences Inc., NJ, USA). The data was analyzed and acquired by employing the WinMDI 2.9 computer program (BD Biosciences Inc., NJ, USA). 


\section{Lentivirus transduction into cell culture}

Human-derived orbital fibroblast cells were incubated in a mixture comprising DMEM containing $20 \%$ FBS, added with antibiotics penicillin (100 U/mL) and streptomycin (100 $\mathrm{U} / \mathrm{mL})$, in a carbon dioxide incubator $\left(5 \% \mathrm{CO}_{2}\right)$ at $37{ }^{\circ} \mathrm{C}$. For induction of $\mathrm{GO}$ inflammation, the human orbital fibroblast cells were exposed to IL$1 \beta(10 \mathrm{ng} / \mathrm{mL})$. Further, the cells were subjected to lentivirus transduction using siBeclin-1 and siAtg-5, small-hairpin RNA (shRNA) of Beclin-1 and Atg-5 respectively. The control group of cells was treated with scrambled RNA (shRNA), and the third group was treated only with FX $(10 \mu \mathrm{M})$. Fibroblast cells induced with GO were treated with FX $(10 \mu \mathrm{M})$ and further subjected to western blotting.

\section{Western blotting}

After washing the cultured fibroblast cells with cold physiological buffer saline, the cells were subjected to ultra-centrifugation at $300 \times \mathrm{g}$ for 5 $\min$ at $4^{\circ} \mathrm{C}$, followed by collection of supernatants. The cells were lysed by exposing them to ice-cold RIPA buffer for $20 \mathrm{~min}$. The lysates were then centrifuged at $4^{\circ} \mathrm{C}$ for $10 \mathrm{~min}$ at $12000 \mathrm{xg}$ to collect the supernatant layer. Bradford assay (BioRad Lab., Inc., CA, USA) was employed for determination of the respective protein concentration. The lysate proteins (30 $50 \mu \mathrm{g})$ were subjected to SDS-PAGE $(10 \% \mathrm{w} / \mathrm{v})$ and then transferred over to the membranes of Hybond ECL nitrocellulose membranes. The membranes were blocked with TBS buffer solution overnight, and were then incubated to rest with specific antibodies against $\beta$-actin, Beclin-1 and Atg-5 (CST Biological Reagents Company, Shanghai, China) at $4^{\circ} \mathrm{C}$ for $24 \mathrm{~h}$. The membranes were washed and then incubated at $25^{\circ} \mathrm{C}$ with HRP conjugated antibodies for $2 \mathrm{~h}$. Densitometric analysis of the corresponding bands was quantified using chemiluminescence reagents and ImageJ software.

\section{Induction of GO in BALB/c}

Twenty-four BALB/c mice were randomized in four groups, each group consisting of 6 animals Control (no GO-induced), GO (GO-induced) FX (FX 50 mg/kg intragastrically) and GO + FX (GOinduced and treated with FX $50 \mathrm{mg} / \mathrm{kg}$ ), Mice from group $\mathrm{GO}$ received intragastric PBS, and $F X$ in respective group was administered with PBS through intragastric route, once daily up to 4 weeks. Immunization with adenovirus AdTSHR289 corresponding to A-subunit expression of thyroid-stimulating hormone receptor. was done to induce GO. The methodology involved propagation of AdTSHR289 and control adenovirus into HEK293 cells (Cell Bank, Shanghai), followed by purification employing ion-exchange column chromatography.

Quantum of viral load was determined by recording absorbance at $260 \mathrm{~nm}$ using UV-visible spectrophotometer. Further, a suspension of AdTSHR289 (10 ${ }^{9}$ particles) suspended in $50 \mu \mathrm{L}$ physiological buffer saline, were delivered intramuscularly into each animal of the GO group and, GO + FX100 group. Mice from the control group and $\mathrm{FX} 100$ received null adenovirus in 50 $\mu \mathrm{L}$ PBS intramuscularly. The animals were administered with respective doses three times at an interval of three weeks. For serum and EOM analysis, the animals were euthanized 4 weeks after the third respective intramuscular dose. The orbital fibroblast cells were collected from individual animals and were preserved for further analysis.

\section{Determination of thyroid peroxidase (Tp) and thyroglobulin (Tg) antibody}

The serum concentration of antibodies corresponding to $\mathrm{Tp}$ and $\mathrm{Tg}$ were quantified using ELISA by employing commercially available ELISA kits (CSB-E11199R, Wuhan, China and Cat. No. 310551, EXPAND, Beijing, China respectively). The procedure was performed according to the instruction manual provided with the respective kits. Physiological buffer saline solution was used to dilute serum samples 5-times, followed by mixing of $50 \mathrm{~mL}$ standard or sample and transferring to each well of the plate containing $50 \mathrm{~mL}$ of the conjugate. The plates were incubated at $37^{\circ} \mathrm{C}$ for $1 \mathrm{~h}$, and then after addition of $50 \mathrm{~mL}$ horseradish-avidin solution, the plates were incubated at $37{ }^{\circ} \mathrm{C}$ for $30 \mathrm{~min}$. Fifty microliters of substrate $A$ and substrate $B$ was put into each well and incubated at $37{ }^{\circ} \mathrm{C}$ for $15 \mathrm{~min}$. Finally, $50 \mathrm{~mL}$ of stop reagent was added to each well and using a microplate reader the optical density was measured at $450 \mathrm{~nm}$.

\section{Real time-polymerase chain reaction (RT- PCR)}

TRIzol reagent (Thermo Fischer Scientific Inc, USA) was used for extraction and isolation of total RNA from the animal orbital fibroblast cells. The total RNA $(1 \mu \mathrm{g})$ was subjected to reverse transcription onto complementary DNA (cDNA) by employing Reverse Transcriptase M-MLV (Takara Bio Inc, Japan) as per the instruction manual, and were amplified using SYBYR Green Master mix. The expression of mRNA 
corresponding to IL-6, IL-8, IL-17, MCP-1 and, TNF- $\alpha$ were analyzed using ABI 7500 RT-PCR system (Thermo Fischer Scientific Inc., USA). Relative mRNA gene expressions were recorded after normalization with $\beta$-actin. The thermocycler conditions employed were as follows: $95^{\circ} \mathrm{C}$ for $1 \mathrm{~min}, 45$ cycles of $95^{\circ} \mathrm{C}$ for 25 sec, $60^{\circ} \mathrm{C}$ for $20 \mathrm{sec}$ and $72^{\circ} \mathrm{C}$ for $20 \mathrm{sec}$. Table 1 indicates the primer sequences adopted for the corresponding mRNA expressions. The threshold cycle $\left(C_{t}\right)$ values were determined by $2^{-\square} C t$ method and the resulting values were recorded as multiples increase compared to control.

\section{8-OHdG and MDA measurement in tears}

Glass capillary tubes were used to collect the basal tear secretions from interior meniscus of both the eyes of individual animals. Possible care was taken to avoid any damage to the eye surface of the subject animals. Fifty microliters of tears were collected and diluted with PBS, and stored at $-60^{\circ} \mathrm{C}$ for further analysis.

Level of 8-OHdG levels and MDA were estimated in the tear secretion as per the manufacturer's instructions using ELISA. The tear samples were centrifuged at $3000 \mathrm{xg}$ for $10 \mathrm{~min}$ and the resulting supernatant was employed for ELISA. The samples of 8-OHdG and MDA were allowed to absorb over the corresponding conjugate plate. The levels of $8-\mathrm{OHdG}$ and MDA were measured by plotting the standard curve using absorbance recoded over a spectrophotometer.

\section{Statistical analysis}

All the data were analysed using SPSS 16.0 (SPSS Inc, Chicago, USA) and GraphPad Prism 8.0.1. The data are expressed as mean \pm standard error of mean (SEM), and analysed using one-way ANOVA. $P<0.01$ was considered statistically significant.

\section{RESULTS}

\section{Effect of FX on cell viability and apoptosis}

In the present study, human orbital fibroblast cells were seeded and were exposed to increasing concentration of $\mathrm{FX}$ and were incubated for $24 \mathrm{~h}$. The cell proliferation was determined by CC-8 assay kit using microplate reader. The cell viability was recorded as the percentage of control group cells. Findings indicated that there was least significant variation between the quantum of cells with or without FX treatment. The results reveal no effect on cell viability after FX treatment (Figure $1 \mathrm{~A}$ ). The results of cell apoptosis assay also revealed that
$24 \mathrm{~h}$ exposure of cells to $1-10 \mu \mathrm{M}$ FX did not indicate any cell apoptosis (Figure $1 \mathrm{~B}$ ).
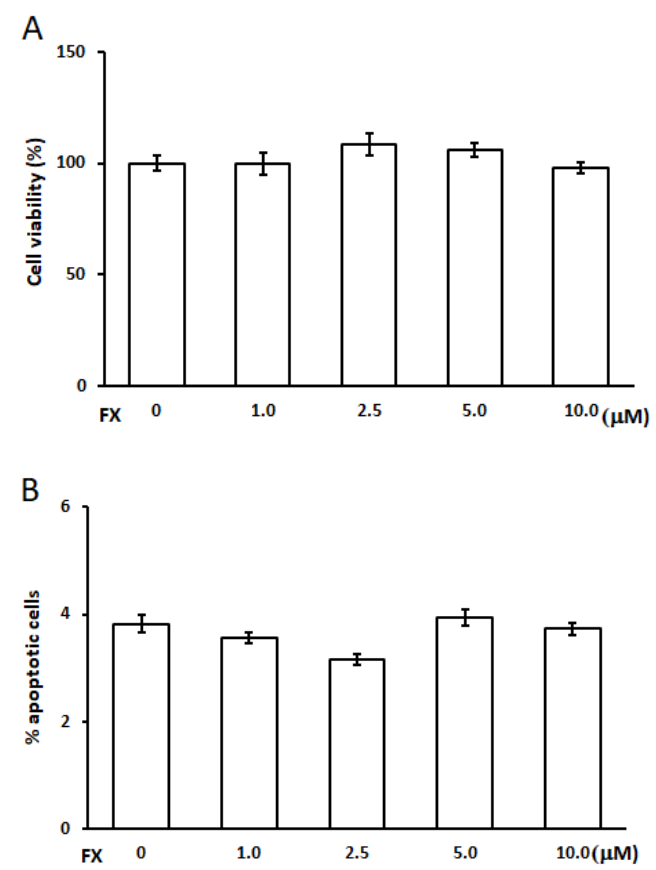

Figure 1: Effect of fucoxanthin on cell viability and apoptosis in cultured human fibroblast cells. (A) Cell viability and cell apoptosis were determined in cultured human fibroblast cells. Cell Counting Kit-8 (CCK-8) assays were performed to determine cell viability. At all the FX concentrations, there was almost complete cell viability. (B) Apoptosis in cultured human orbital fibroblast cells, at variable FX concentrations was determined using flow cytometer. At all the FX concentrations, the percentage cell apoptosis was less than $4 \%$

\section{Effect of FX on Beclin-1 and Atg-5 expression}

To explore, the involvement of $F X$ in the reduction of inflammation, human orbital fibroblasts were treated with IL-1 $\beta$, which were further treated with FX. Beclin-1 is known as a critical regulator of autophagy, and Atg-5 is responsible for sequestration process during autophagy. The human orbital fibroblasts were transfected with siBeclin-1 and si-Atg-5, which resulted in a significant reduction in the Beclin-1 and Atg-5 expression $(p<0.001)$ (Figure $2 \mathrm{~A}$ and $B)$. The data support the fact that $F X$ results in inhibition of beclin-1 and Atg-5 that may further result into an attenuation of autophagy.

\section{Effect of FX on GO-induced mice model}

For the present study, BALB/c mice were employed. The animals were divided into four groups. The control group received PBS through intragastric route and was injected with null 
adenovirus vectors, and the animal group designated as the GO group was induced with GO by immunization with Ad-TSHR289 3-times at three weeks interval. The third group, that is, the FX group was administered with FX (100 $\mathrm{mg} / \mathrm{kg}$ ) but were not GO-induced. The remaining animal group were induced with GO, and received FX intragastrically, FX100 (100 mg/kg). After four weeks of the third injection of AdTSHR289, the GO-induced animals reflected both swollen eyelids and continuous discharge from the eye.
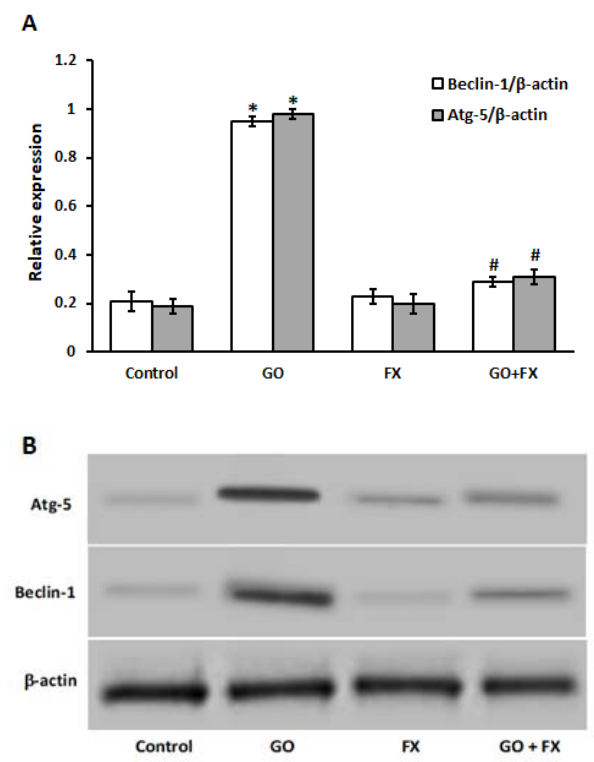

Figure 2: Human orbital fibroblasts were treated with IL-1 $\beta$, and further with FX. (A) Densitometric analysis of the (B) Western blot results obtained. Human orbital fibroblasts were transfected with siBeclin-1 and si-Atg5 , which resulted in a significant reduction in beclin-1 and Atg-5 expression $(p<0.001)$. FX resulted in Beclin-1 and Atg-5 inhibition; ${ }^{*} p<0.001$, versus control; $\# p<0.01$, versus GO

\section{Effect of FX on Tp and Tg antibody levels}

The serum concentration of $\mathrm{Tp}$ and $\mathrm{Tg}$ antibody levels were measured by commercially available ELISA kit. $\mathrm{Tp}$ and $\mathrm{Tg}$ antibody levels were significantly elevated in animals that were immunized with Ad-TSHR289, in comparison to the control group. Administration of FX in GOinduced animal groups indicated a reduction in the elevated levels of $\mathrm{Tp}$ and $\mathrm{Tg}$, in a dosedependent manner (Figure $3 \mathrm{~A}$ and $\mathrm{B}$ ).

\section{Effect of FX on inflammatory mediators in orbital fibroblast of GO-induced mice}

One of the key players in GO pathogenesis is inflammatory mediators. In the present study, GO was developed through Ad-TSHR289 adenovirus immunization. The resulting inflammation was assessed by measuring the overexpression of mRNA corresponding to IL-6, IL-8, IL-17, MCP-1, and TNF- $\alpha$. The increased mRNA expression of inflammatory mediators was quantified using RTqPCR. IL-6, IL-8, and IL-17 levels were remarkably elevated in the orbital fibroblast cells of GO-induced animals. Compared to the normal animals, the relative expression of IL-6, IL-8, and IL-17 mRNA was elevated approximately by $10-$ fold in the orbital fibroblasts derived from GOinduced animals. Administration of FX in GOinduced animals revealed a significant reduction in the elevated mRNA expression of IL-6, IL-8, and IL-17. Among the representative inflammatory mediators, IL-17 mRNA depicted a significant reduction in its relative expression, compared to IL-6 and IL-8 (Figure 4A).

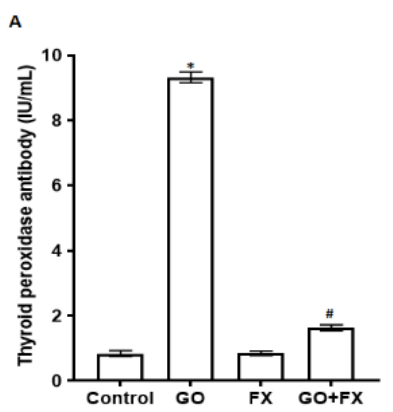

B

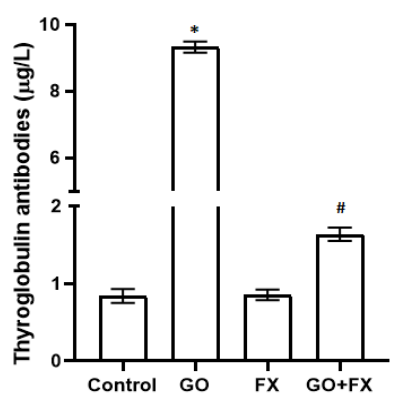

Figure 3: Serum concentration of (A) thyroid peroxidase and $(B)$ thyroglobulin antibody levels were measured by commercially available ELISA kit. Immunization with Ad-TSHR289 lentivirus induced $\mathrm{GO}$, revealed by marked elevation the serum concentrations of $\mathrm{Tp}$ and $\mathrm{Tg}$ antibodies, compared to control. Administration of FX (100 mg/kg) resulted into significant reduction in the $\mathrm{Tp}$ and $\mathrm{Tg}$ antibodies, indicating its therapeutic efficacy in the treatment of GO; * $p<0.001$, versus control; $\# p<0.01$, versus GO

A notable increase in the expression of MCP-1 and TNF- $\alpha$ mRNA was observed in the orbital fibroblast derived from animals that were induced with GO compared to that from the control group. There was 7- and 5-fold rise in the expression level of MCP- 1 and TNF- $\alpha$ mRNA respectively, 
in the fibroblast collected from GO-induced animals. Administration of FX in animals induced with $\mathrm{GO}$, resulted into a significant drop in the expression of MCP-1 and TNF- $\alpha$ mRNA. The mRNA expression of MCP-1 and TNF- $\alpha$ in the orbital fibroblast cells of GO-induced animals were effectively normalized after administration of FX (Figure 4B). Respective western blot depicting expression of IL-6, IL-8, IL-17, TNF-a and MCP-1 are shown in Figure 4C.
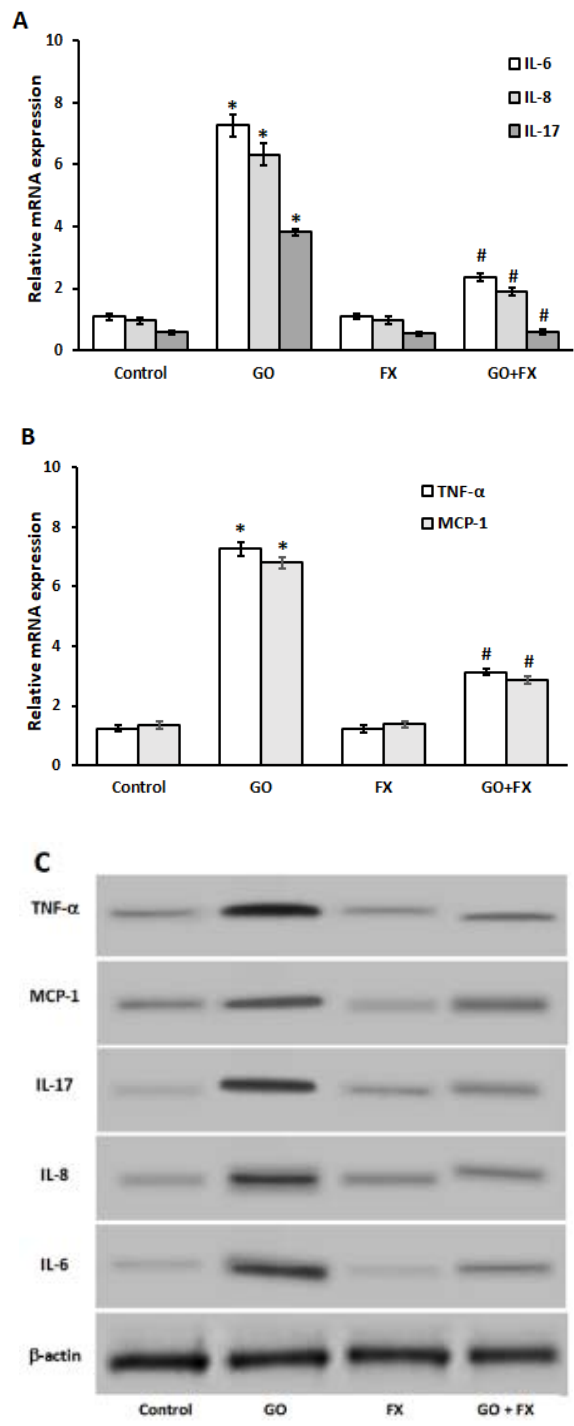

Figure 4: Effect of FX on inflammatory mediators in orbital fibroblast of Ad-TSHR289 adenovirus induced $\mathrm{GO}$ in mice. The overexpression of mRNA corresponding to IL-6, IL-8, IL-17, MCP-1, and TNF- $\alpha$ was quantified using RT-PCR. (A) IL-6, IL-8, and IL-17 levels were significantly increased in the orbital fibroblast cells of GO-induced animals. Administration of $\mathrm{FX}$ in $\mathrm{GO}$-induced animals revealed a significant reduction in the elevated mRNA expression of IL-6, IL8 , and IL-17, as indicated by densitometric analysis. (B) Expression of MCP-1 and TNF- $\alpha$ mRNA was increased in the orbital fibroblast derived from animals that were induced with $\mathrm{GO}$ compared to that from the control group. Administration of FX in animals induced with GO, resulted into a significant drop MCP-1 and TNF- $\alpha$ mRNA expression. (C) Western blot indicating expression of inflammatory mediators in control, GO, $\mathrm{FX}$ and GO + FX group of animals; ${ }^{*} p<0.001$, versus control; \#p $<0.01$, versus $\mathrm{GO}$

\section{Effect of FX on 8-OHdG and MDA levels}

The average concentration of $8-\mathrm{OHdG}$ and MDA in the animal tears of the control group was found to be $16.12 \mathrm{ng} / \mathrm{mL}$ and $1.62 \mathrm{pmol} / \mathrm{mL}$. In animals induced with GO, the mean levels of these oxidative markers were significantly raised to $68.91 \mathrm{ng} / \mathrm{mL}$ and $6.92 \mathrm{pmol} / \mathrm{mL}$. The elevated values of $8-\mathrm{OHdG}$ and MDA reveal the possible oxidative damage in the orbital fibroblast during GO. There is a significant difference in the levels of 8-OHdG and MDA in animal tears that were induced with GO and treated with FX. In GOinduced and FX treated animals the level of 8OHdG was reduced to $22.67 \mathrm{ng} / \mathrm{mL}$ and MDA was reduced to $1.73 \mathrm{pmol} / \mathrm{mL}$ (Figure 5).

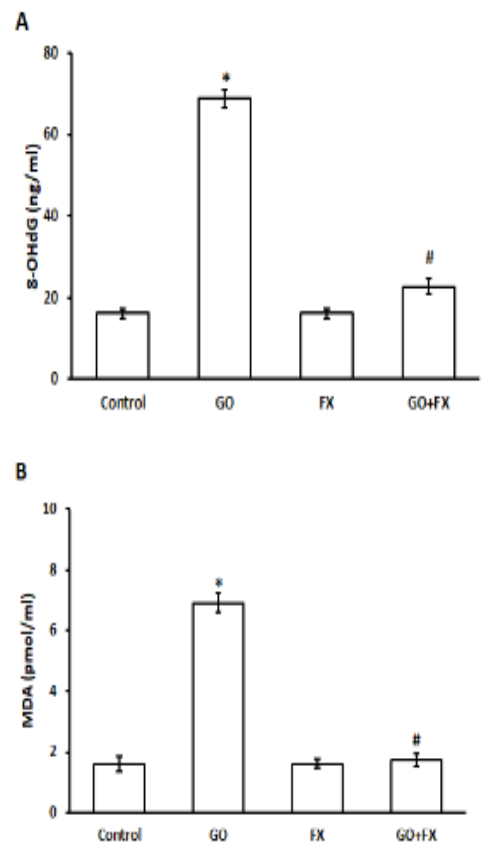

Figure 5: Effect of FX on 8-OHdG and MDA levels in tear secretions of GO-induced mice. Tear secretions indicated marked rise in the levels of oxidative markers (A) 8-OHdG and (B) MDA after induction of GO. FX administration significantly reduced the levels of $8-\mathrm{OHdG}$ in $\mathrm{GO}$ induced mice. FX induces antioxidant effect in $\mathrm{GO}$ induced mice; ${ }^{*} p<0.001$, versus control; $\# p<0.01$, versus GO

\section{DISCUSSION}

Graves orbitopathy is an incurable and threatening autoimmune process that involves all 
ocular orbital tissues and hence have long been a big challenge to researchers involved in ophthalmology and endocrinology [7]. Research conducted on $\mathrm{GO}$ advocates IL-17 production by TH17 cells, that potentiates the expression of chemokines and cytokines responsible for severe inflammation and subsequent propagation of the disease [10]. Orbital fibroblasts, which are autoimmune targets and effector cells in GO, are another major source of cytokines. Several cytokines involved in the development and progress of $\mathrm{GO}$, have been detected in orbital tissues, such as IL-1 $\beta$, IL-6, IL-8, and IL-17 [19]. IL-1 $\beta$, a member of IL-1 cytokine family, has been established to be actively involved in the induction of several inflammatory mediators, that is linked with the pathogenesis of $\mathrm{GO}$, encompassing IL-6, IL-8, and IL-17. IL-1 $1 \beta$ is also known to accelerate autophagic activity in orbital fibroblast cells [20].

IL-17and Th17 cells are actively linked with the pathogenesis of GO. IL-17 mRNA expression is found to be dramatically increased during the active stages of GO. Combination of IL-23 with its receptors over the cell surfaces potentiates the expression of IL- $6, \mathrm{IL}-1 \beta$, and TNF- $\alpha$, which further triggers differentiation of Th17 cells and IL-17 secretion, thereby accelerates GO. In addition, IL-17 combines with dendritic cell surface IL-17 receptors, which secretes IL-23 and enhances Th17 cell differentiation and IL-17 release [21].

Fucoxanthin, a red marine carotenoid found in seaweeds, has been known to be effective against inflammation, diabetes, cancer, and obesity. In a lipopolysaccharide-induced murine macrophage RAW 264.7 cell model, FX produced an anti-inflammatory effect by inhibition of nitric oxide, prostaglandin, IL-6, IL-8, IL-1 $\beta$, through NF-kB suppression and MAPK phosphorylation [14]. It has been reported that FX reduces the activity of monocyte chemoattractant protein-1 (MCP-1) [16]. Antioxidant activity of FX has been critically attributed to its chemical structure that comprises of the allenic bond, hydroxyl group, and epoxide group.

Considering the intricate involvement of IL-6, IL8, IL-17, and TNF- $\alpha$ in the immunological progression of $\mathrm{GO}$, downregulation of their production could prove as an effective GO treatment. Hence the research was envisaged to elucidate the possible therapeutic and protective effects of $\mathrm{FX}$ in $\mathrm{GO}$.

Results of cell viability and apoptosis studies indicated FX did not have any significant effect.
FX did not indicate any damage to the cultures of human orbital fibroblast cells. Investigation to explore the in vitro protective effects of FX in orbital fibroblast cells was performed by transfection of lentivirus into IL-1 $\beta$ pretreated cells. To mimic $\mathrm{GO}$ in vitro, the cells were treated with $\mathrm{IL}-1 \beta$ and were further transfected with siBeclin-1 and siAtg-5. FX resulted in inhibition of Beclin-1 and Atg-5 proteins, that could promote autophagy. Thus, FX attenuated autophagy by silencing Beclin-1 and Atg-5, in over-expression of inflammatory mediators in human orbital fibroblast induced through IL-1 $\beta$.

Finally, the protective effect of FX in GO-induced mice was investigated. BALB/c mice were randomized in four groups Control, GO, FX and $\mathrm{GO}+\mathrm{FX}$. Prior to induction of $\mathrm{GO}$, the animals were administered with FX (50 mg/kg/day) for 4 weeks by the intragastric route. GO was developed through adenovirus immunization corresponding to the expression of Ad-TSHR289. The induction of $\mathrm{GO}$ was validated by measuring serum levels of $\mathrm{Tp}$ and $\mathrm{Tg}$ antibodies by ELISA. Compared to control group animals, a statistically significant rise in the serum levels of $\mathrm{Tp}$ antibodies and $\mathrm{Tg}$ antibodies in animals of $\mathrm{GO}$ and GO+FX group signify successful induction of $\mathrm{GD}$. Animals from $\mathrm{GO}+\mathrm{FX}$ indicated a significant reduction in the levels of $\mathrm{Tp}$ antibodies and $\mathrm{Tg}$ antibodies in serum compared to the GO group. Administration of FX alone did not indicate a marked alteration in the levels of antibody titer in animal serum. The results indicated the therapeutic efficacy of FX in the treatment of GD and possibly GO in mice model.

Inflammation is the key determinant in the progression of GO. To explore the antiinflammatory potential of $\mathrm{FX}$, expression of mRNA corresponding to IL-6, IL-8, IL-17, MCP-1, and TNF- $\alpha$ were quantified using RT-qPCR. Expression of IL-6 and IL-8 were markedly elevated in orbital tissues collected from animals induced with $\mathrm{GO}$, in comparison to the control group. A marked reduction in the expression of IL-6 and IL-8 was observed in GO-FX group.

Involvement of $\mathrm{IL}-17$ in various processes in orbital fibroblasts is a major determinant of inflammation during GO [22]. In the present investigation, overexpression of IL-17 mRNA was revealed in orbital fibroblast recovered from animals induced with GO. Treatment with FX indicated markedly statistically significant underexpression of IL-17 mRNA. Therefore, it can be assured that FX actively attenuates IL-17 secretion and thereby effectively induces a protective effect in orbital fibroblast tissues derived from animals induced with GO. 
Among the several markers of oxidative stress, 8-OHdG and MDA are the most commonly explored products of DNA oxidation and peroxidation of lipids. The rise in $8-\mathrm{OHdG}$ levels corresponds to the reaction between hydroxyl radical at the guanine base in the DNA, whereas MDA is generated from oxidative breakdown of unsaturated fatty chains [24]. Hydroxyl radicals initiate the release of inflammatory cytokines, that actively participate in the development of $\mathrm{GO}$ [24]. Reduction in the levels of these oxidative markers will definitely contribute to the treatment strategies utilized in GO. In the present investigation, levels of $8-\mathrm{OHdg}$ and MDA were significantly raised $(p<0.001)$ in tear secretions collected from the animal eyes induced with GO. FX actively attenuates the presence of oxidative markers in the tar secretions collected from the eyes of GO-induced experimental animals.

\section{CONCLUSION}

The findings of this investigation suggest that $\mathrm{FX}$ attenuates the autophagy induced by IL-1 $\beta$ in human orbital fibroblasts in vitro, through Beclin1 and Atg-5 silencing. This is the first study, to the best of our knowledge, that has proposed the anti-inflammatory effect of $\mathrm{FX}$ in the orbital fibroblasts of GO-induced BALB/c mice, via attenuation of IL-17. Thus, FX is a potential novel molecule for the treatment of inflammation and oxidation during $\mathrm{GO}$ in mice.

\section{DECLARATIONS}

\section{Acknowledgement}

The authors would like to acknowledge the Head of Department of Nuclear Medicine and Department of Nephrology, Xingtai People's Hospital, China for continuous support for this work.

\section{Conflict of interest}

No conflict of interest is associated with this work.

\section{Contribution of authors}

We declare that this work was done by the authors named in this article and all liabilities pertaining to claims relating to the content of this article will be borne by the authors.

\section{Open Access}

This is an Open Access article that uses a funding model which does not charge readers or their institutions for access and distributed under the terms of the Creative Commons Attribution License (http://creativecommons.org/licenses/by/ 4.0) and the Budapest Open Access Initiative (http://www.budapestopenaccessinitiative.org/rea d), which permit unrestricted use, distribution, and reproduction in any medium, provided the original work is properly credited.

\section{REFERENCES}

1. Garrity J, Bahn R. Pathogenesis of Graves ophthalmopathy: Implications for prediction, prevention, and treatment. Am J Ophthalmol 2006; 142(1): 147153.e2.

2. Kuriyan AE, Phipps RP, Feldon SE. The eye and thyroid disease. Curr Opin Ophthalmol 2008; 19(6): 499-506.

3. Bahn RS. Graves' ophthalmopathy. N Engl J Med 2010; 362(8): 726-738.

4. Lehmann GM, Feldon SE, Smith TJ, Phipps RP. Immune mechanisms in thyroid eye disease. Thyroid 2008; 18(9): 959-965.

5. Bartalena L, Pinchera A, Marcocci C. Management of Graves' ophthalmopathy: reality and perspectives. Endocr Rev 2000; 21(2): 168-199.

6. Valyasevi RW, Harteneck DA, Dutton CM, Bahn RS. Stimulation of adipogenesis, peroxisome proliferatoractivated receptor-gamma (PPARgamma), and thyrotropin receptor by PPARgamma agonist in human orbital preadipocyte fibroblasts. J Clin Endocrinol Metab 2002; 87(5): 2352-2358.

7. Gianoukakis AG, Khadavi N, Smith TJ. Cytokines, Graves' disease, and thyroid-associated ophthalmopathy. Thyroid 2008; 18(9): 953-958.

8. Saitoh O, Nagayama Y. Regulation of Graves' hyperthyroidism with naturally occurring CD4+CD25+ regulatory $T$ cells in a mouse model. Endocrinol 2006; 147(5): 2417-2422.

9. Shi Y, Wang H, Su Z, Chen J, Xue Y, Wang S, Xue Y, He $Z$, Yang $H$, Zhou $C$ et al. Differentiation imbalance of Th1/Th17 in peripheral blood mononuclear cells might contribute to pathogenesis of Hashimoto's thyroiditis. Scand J Immunol 2010; 72(3): 250-255.

10. Li D, Cai W, Gu R, Zhang Y, Zhang $H$, Tang $K, X u P$, Katirai $F$, Shi $W$, Wang $L$ et al. Th17 cell plays a role in the pathogenesis of Hashimoto's thyroiditis in patients. Clin Immunol 2013; 149(3): 411-420.

11. Wei $H$, Guan M, Qin $Y$, Xie C, Fu X, Gao F, Xue Y. Circulating levels of miR-146a and IL-17 are significantly correlated with the clinical activity of Graves' ophthalmopathy. Endocr J 2014; 61(11): 1087-1092.

12. Zijun C, Chun L, Qiang L. The change of Th17 lymphocytes and cytokines in autoimmune thyroid diseases. Immunological J 2011; 27: 49-52 (In Chinese).

13. Zheng $L$, Ye $P$, Liu $C$. The role of the $I L-23 / I L-17$ axis in the pathogenesis of Graves' disease. Endocr $J$ 2013; 60(5): 591-597. 
14. Yang YP, Tong QY, Zheng SH, Zhou MD, Zeng YM, Zhou TT. Anti-inflammatory effect of fucoxanthin on dextran sulfate sodium-induced colitis in mice. Nat Prod Res 10.1080/14786419.2018.1528593

15. Satomi Y. Antitumor and Cancer-preventative Function of Fucoxanthin: A Marine Carotenoid. Anticancer Res 2017; 37: 1557-1562.

16. Tan $C P$, Hou YH. First evidence for the anti-inflammatory activity of fucoxanthin in high-fat-diet-induced obesity in mice and the antioxidant functions in PC12 cells. Inflam 2014; 37(2): 443-450.

17. Kawashima T. A marine carotenoid, fucoxanthin, induces regulatory $T$ cells and inhibits Th17 cell differentiation in vitro. Biosci Biotechnol Biochem 2011; 75(10): 20662069.

18. World Health Organization. Principles of laboratory animal care. WHO Chron 1985; 39: 51-56.

19. Chen B, Tsui S, Smith TJ. IL-1 beta induces IL-6 expression in human orbital fibroblasts: identification of an anatomic-site specific phenotypic attribute relevant to thyroid-associated ophthalmopathy. J Immunol 2005; 175(2): 1310-1319.
20. Hwang CJ, Afifiyan N, Sand D, Naik V, Said J, Pollock SJ, Chen B, Phipps RP, Goldberg RA, Smith TJ et al. Orbital fibroblasts from patients with thyroid-associated ophthalmopathy overexpress CD40: CD154 hyperinduces IL-6, IL-8, and MCP-1. Invest Ophthalmol Vis Sci 2009; 50(5): 2262-2268.

21. Smith TJ. Orbital fibroblasts exhibit a novel pattern of responses to proinflammatory cytokines: potential basis for the pathogenesis of thyroid-associated ophthalmopathy. Thyroid 2002; 12(3): 197-203.

22. Kikly K, Liu L, Na S, Sedgwick JD. The IL-23/Th (17) axis: therapeutic targets for autoimmune inflammation. Curr Opin Immunol 2006; 18(6): 670-675.

23. Chang YT, Chang WN, Tsai NW, Huang CC, Kung CT, Su YJ, Lin WC, Cheng BC, Su SM, Chiang YF et al. The roles of biomarkers of oxidative stress and antioxidant in Alzheimer's disease: a systematic review. Biomed Res Int 2014; 2014: 182303.

24. Karihtala P, Kauppila S, Puistola U, Jukkola-Vuorinen A. Divergent behaviour of oxidative stress markers 8hydroxydeoxyguanosine (8-OHdG) and 4-hydroxy-2nonenal (HNE) in breast carcinogenesis. Histopathol 2011; 58(6): 854-862. 